\title{
The Role of the Local Host Community's Involvement in the Development of Tourism: A Case Study of the Residents' Perceptions toward Tourism on the Route of Santiago de Compostela (Spain)
}

\author{
Jakson-Renner-Rodrigues Soares ${ }^{1,2, * \mathbb{D}}$, Maria-Francisca Casado-Claro ${ }^{3}$, María-Elvira Lezcano-González ${ }^{4}$, \\ María-Dolores Sánchez-Fernández ${ }^{1}$ (D), Larissa-Paola-Macedo-Castro Gabriel ${ }^{5}$ and Maria Abríl-Sellarés ${ }^{6}$
}

Citation: Soares, J.-R.-R.;

Casado-Claro, M.-F.; Lezcano-González,

M.-E.; Sánchez-Fernández, M.-D.;

Gabriel, L.-P.-M.-C.; Abríl-Sellarés, M.

The Role of the Local Host

Community's Involvement in the

Development of Tourism: A Case

Study of the Residents' Perceptions

toward Tourism on the Route of

Santiago de Compostela (Spain).

Sustainability 2021, 13, 9576. https://

doi.org/10.3390/su13179576

Academic Editors: Ángeles Rubio-Gil and Jesús-Alberto Valero-Matas

Received: 25 July 2021

Accepted: 17 August 2021

Published: 25 August 2021

Publisher's Note: MDPI stays neutral with regard to jurisdictional claims in published maps and institutional affiliations.

Copyright: (c) 2021 by the authors. Licensee MDPI, Basel, Switzerland. This article is an open access article distributed under the terms and conditions of the Creative Commons Attribution (CC BY) license (https:// creativecommons.org/licenses/by/ $4.0 /)$.
1 Department of Business, University of A Coruña, 15001 A Coruña, Spain; maria.sanchezf@udc.es

2 Master in Tourism Business Management, Universidade Estadual do Ceará, Fortaleza 60714-903, Brazil

3 Department of Economics and Business, Universidad Europea, 28670 Madrid, Spain;

francisca.casado@universidadeuropea.es

4 Department of Humanities, University of A Coruña, 15001 A Coruña, Spain; m.lezcano@udc.es

5 Tourism, Economy and Sustainability Research Group, Universidade Estadual do Ceará,

Fortaleza 60714-903, Brazil; larapgabriel@gmail.com

6 Department of Tourism, Universitat Autònoma de Barcelona, 08193 Bellaterra, Spain; maria.abril@uab.cat

* Correspondence: jakson.soares@udc.gal

\begin{abstract}
As an economic, social, and cultural activity, tourism shapes the relationship between visitors and local communities in tourist destinations. While tourism generates economic growth and employment opportunities for residents, its benefits come with a social cost. This article highlights the results of an online survey that was carried out at the beginning of 2021 in the seven major Galician cities along the Route of Santiago de Compostela (the Way of St. James) in Spain, which is a historical, natural, and cultural tourist attraction that is inscribed in the UNESCO's World Heritage List in the category of cultural assets. The goal of the research work was to get to know first-hand the opinion of local communities about the positive and negative effects of tourism in their cities, on the Route of Santiago, and in the region of Galicia as a whole. Research work shows that residents' perception of tourism leans toward the positive side, although it also reveals the need for tourism planners to involve host communities in tourism development. This research study about a World Heritage site should prove useful for political decision makers, tourism planners, and experts, both in Galicia and elsewhere.
\end{abstract}

Keywords: tourism effects; Route of Santiago de Compostela; local communities; tourism perceptions; participatory tourism development; overtourism; post-COVID-19 recovery; sustainable tourism

\section{Introduction}

The sense of hospitality in tourism is partially shaped by the involvement of the local host community in tourism-related activities, which is related to the perception that the local community itself has of the tourism activity taking place in their places of residence or work. In historical and cultural destinations, the intertwined realities of tourism-as an economic, social, and cultural activity-influence host communities in various ways. On the other hand, from a systemic perspective, the local community's perception of tourism shapes its behavior toward tourists and, consequently, the tourists' experience in the destination.

As tourists flock to cultural and historical heritage sites in significant numbers, local host communities experience some disturbances. In some cases, mass tourism might even cause major disruptions, as is the case with the phenomenon of "overtourism," whereby a destination is visited by excessive numbers of tourists, which is lucrative for businesses 
but detrimental to the residents. The UNWTO recognizes that terms such as "overtourism" or "tourismphobia" not only "reflect challenges of managing growing tourism flows into urban destinations" but also "the impact of tourism on cities and its residents" in their two-volume report "Overtourism"? Understanding and Managing Urban Tourism Growth beyond Perceptions, which includes 18 case studies from cities around the world, ranging from widely reported cases, such as those of Barcelona, Venice, and New York, to other less salient locations, such as Buchon Hanok Village in Seoul (South Korea) or Hangzhou and Macao (China) [1]. Koens, Postma, and Papp [2] blame the "marketability and popularity" of the term for its entry into the academic debate, even though, in their opinion, it is still ill-defined and difficult to operationalize. Indeed, the tools available to do so are still limited. In our literature review, the most widely implemented mechanism we found was tourism carrying capacity (TCC), which can be measured using technological solutions (such as sensors and cameras placed on strategic locations to count the number of people entering an area, as well mobile geolocation tools coupled with artificial intelligence and machine learning), as was the case in the simulations carried out by Camatti et al. [3] in the UNESCO World Heritage Site of Dubrovnic (Croatia).

While TCC presents some weaknesses that have been criticized, it still proves useful. Controlling the number of people accessing public spaces using technological solutions can prevent tourist areas from getting crowded but, as the UNWTO recognizes [1] and Koens et al. [2] contend when discussing the myths of overtourism, public spaces are shared by a variety of stakeholders (commuters, workers, delivery services, residents and others), i.e., tourists are not the only ones using them. On the other hand, smart solutions have limitations of their own and their virtues are sometimes overestimated. Moreover, it takes an extraordinary effort for local governments to develop new apps and get citizens and visitors to use them, when our smartphones are already loaded with apps we do not use.

Tourism is a double-edged sword that brings about both positive and negative effects; therefore, it is imperative to manage tourism to maximize its positive effects while its adverse effects are minimized. As Camatti et al. [3] point out, assessing the benefits and costs of tourism is not an easy task, as different stakeholders have different perceptions of the same reality. Moreover, since those perceptions are dynamic, they will be shaped over time on the base of the interaction between visitors, residents, and the tourism industry, which is marked by their respective behaviors and the evolution of the tourism destination itself from its embryonic stage to its growth, maturity, and decline, following the lines of Butler's destination life cycle theory (TALC). On the other hand, Koens et al. [2] undertake a historical revision of tourism's negative impacts and identify overcrowding in public spaces, inappropriate behavior by tourists, touristification of city centers, residents being pushed out of residential areas ("crowding out"), and pressure on the local environment amongst its causes.

In contrast, crises, such as the one that was globally spawned by the COVID-19 pandemic, highlight the importance of tourism activities for the economies of destinations, or rather the impact of the lack of it when a severe disruption happens. The word crisis in Japanese combines two Chinese characters meaning "danger" and "opportunity," whereas in ancient Greek, its semantic field includes not only "a turning point," but also "choice" and "judgment". Thus, crises should be seen not only as dark times in which human systems as we know them collapse, but also as opportunities for planning better futures. Along this line, natural and human-made disasters are seen as opportunities to "build back better," not only more resistant infrastructures but also more resilient communities. From an evolutionary perspective, disasters are even seen as a chance to "bounce forward" and to create something better and more sustainable than what was left behind, in contrast to the traditional definition of resilience as the ability of a system of "bouncing back" to its previous state.

As far as the COVID-19 crisis has made governments and institutions react and become aware of the need for a structural change in their growth models in economic, 
social, and environmental terms, the crisis could act as a driver for changes in policies, both in the short-term and the mid-and-long-term [4]. Countries worldwide recognize that the lockdown period has caused a drop in the activity of entire economic sectors, such as the construction and automotive industries and the tourism sector.

Therefore, the COVID-19 pandemic has been seen around the world as an opportunity to build more resilient and sustainable systems, as can be inferred from the fact that the words "resilience" and "sustainability" appear prominently in the names of various policies at international, regional and national levels. Post-COVID-19 recovery and resilience plans in Spain, in the EU, and elsewhere revolve around the so-called "green recovery," focusing on the energy and transportation sectors and smart manufacturing. In line with this, the European Commission has launched the "European Green Deal," which aims to make the economy of the EU Member States sustainable through measures that turn climate and environmental challenges into opportunities [5]; other priorities in the EU include investing in creating new jobs and protecting existing ones [4].

These lines of action materialized in the European Union's NextGenerationEU, which is a stimulus package that is linked to the Multiannual Financial Framework 2021-2027, whose funds will be allocated to the member states (up to 312.5 billion EUR in grants and up to 360 billion EUR in loans) to finance the necessary investments in reforms to manage the crisis (672.5 billion EUR managed through the "Recovery and Resilience Facility"). Seven flagship areas for investment and reform are identified, amongst which, services in general and tourism in particular are not mentioned [6].

In some areas of Spain, recovery plans aim to diversify the economy away from the tourist monoculture. However, tourism remains an essential source of income that is capable of boosting and regenerating local economies in many destinations. In prepandemic times, tourism made up $11.8 \%$ of Spain's GDP and accounted for 2.6 million direct jobs (13.5\% of employment) according to OECD data for 2018 [7]. In sum, tourism should therefore be given due attention in Spain's Recovery, Transformation and Resilience Plan as a profitable and promising economic industry that should be included in recovery plans from a sustainable perspective that is aligned with the Plan's four transversal axes: ecological transition, digital transformation, social and territorial cohesion, and gender equality [8].

In this context, it is necessary to analyze the role that the local community plays in local development. Political decision makers and tourism planners need to understand the residents' perceptions and their influence on sustainable development to minimize the negative impacts of tourism while increasing the community's wellbeing, thus adding value to the tourist experience in the destination. The COVID-19 pandemic has brought about an intense debate about the future of tourism as we have known it and the need to make of it a more sustainable activity. Experts recommend using "demarketing" to reduce or shift demand, combined with social marketing to educate consumers by promoting responsible tourism and the use of smart digital solutions to control the flow of tourists, which is something that could have been ill-considered in other times but that can now be justified in the name of social distancing and sanitary rules [3]. Along the same line, experts call for new metrics beyond the numbers of tourist arrivals to measure tourism achievements and, in parallel, the separation of management and marketing activities in DMOs in order to prevent regulatory capture when having the functions of promoting tourism arrivals and controlling the affluence of tourists under the same umbrella, propitiating the ensuing conflicts of interest. The message is clear: we need to prepare for a world post COVID-19 while co-existing with it for a still undetermined period.

This article aims to fill a gap in recent research by focusing on cultural heritage and World Heritage Sites, where the role that the local community is currently insufficiently explored. Most of the research conducted in the field of tourism focuses mainly on tourist consumption and consumer behavior at a local level. Most studies we came across in our literature review neglected the impact of tourist activity in the everyday life of local communities, even though this is one aspect that must be considered in tourism planning 
to build long-term sustainability into tourism. Therefore, our research aimed to make a meaningful contribution to this insufficiently researched topic by examining Santiago de Compostela's local community perceptions toward tourism from both social and economic perspectives. Our research also inquired about residents' interest in backing the local tourist activity and, more specifically, about their support for tourism in the Route of Santiago.

Therefore, this study's general objective was to throw some light on the role of local communities in tourism development by analyzing the perceptions and attitudes of Galician residents toward tourism on the Route of Santiago de Compostela and studying their interest in the development of tourism. The research was carried out through fieldwork involving data collection in the seven main Galician cities located along the Route of Santiago. The data were collected in a ten-week period between February 2021 and April 2021. Although a total of 958 questionnaires were answered in our survey, due to the requirement of having a steady relationship with the city, 159 of the responses were discarded since the respondents did not either live or work in any of the cities included in the study.

The results show that tourism on the Route of Santiago de Compostela was perceived chiefly in a positive light by the local population. Out of the positive and negative impacts assessed in this study (15 items in total), the averages obtained in the perceptions of the positive effects were very high, whereas the averages were very low for the negative ones. Another remarkable result was that almost $87 \%$ of the population sample would be willing to somehow become involved in tourism planning and development in their cities. Moreover, diverse values for the perception of both positive and negative tourism effects were obtained in each of the seven Galician cities in our study and an ANOVA test was carried out to confirm the validity of the results. This article contends that obtaining a proper understanding of these local differences is necessary in order to be able to take actions to improve the perception of tourism of the local community since residents are the ones to experience first-hand both the benefits and disturbances of tourism.

\subsection{The Cultural, Historical, and Economic Significance of the Route of Santiago}

According to UNESCO [9], the Route of Santiago de Compostela (commonly known in Spanish as "Camino de Santiago") is an extensive interconnected network of pilgrimage routes departing from different points in Europe and whose ultimate destination is the tomb of the Apostle James the Greater in Santiago de Compostela in Galicia, which is a region located in Spain's northwest. Therefore, in this text, we have opted for preserving the denominations "Route of Santiago de Compostela" and "Route of Santiago" for short, following the translation on UNESCO's website; however, the name can also be translated as "Pilgrim's Way to Santiago," "the Way of St. James," or "Saint James' Way," among others. A multilingual map of the different routes to Santiago within the region of Galicia can be found in Figure 1.

From a cultural perspective, as the final destination of the pilgrims, the city of Santiago de Compostela is a renowned urban international tourism destination that receives thousands of visitors annually, who arrive in the city attracted by the religious and spiritual significance of its heritage. The city, which is located in the northwestern Spanish province of A Coruña in the region of Galicia became a pilgrimage destination for millions of Europeans during the Middle Ages after the tomb of the Apostle James the Greater (Santiago) was discovered in the ninth century. As a result, it soon became one of the world's foremost Christian pilgrimage destinations, alongside Rome and Jerusalem, and in our days it still is.

UNESCO has registered three sites in its renowned World Heritage List: the Old Town of Santiago de Compostela [10] from 1985 and the Routes of Santiago de Compostela: Camino Francés and the Routes of Northern Spain [11], from 1993 and 2015, respectively. Besides recognizing its value, the UNESCO listing has given even more fame to both the Routes of Santiago de Compostela and the Old Town. 


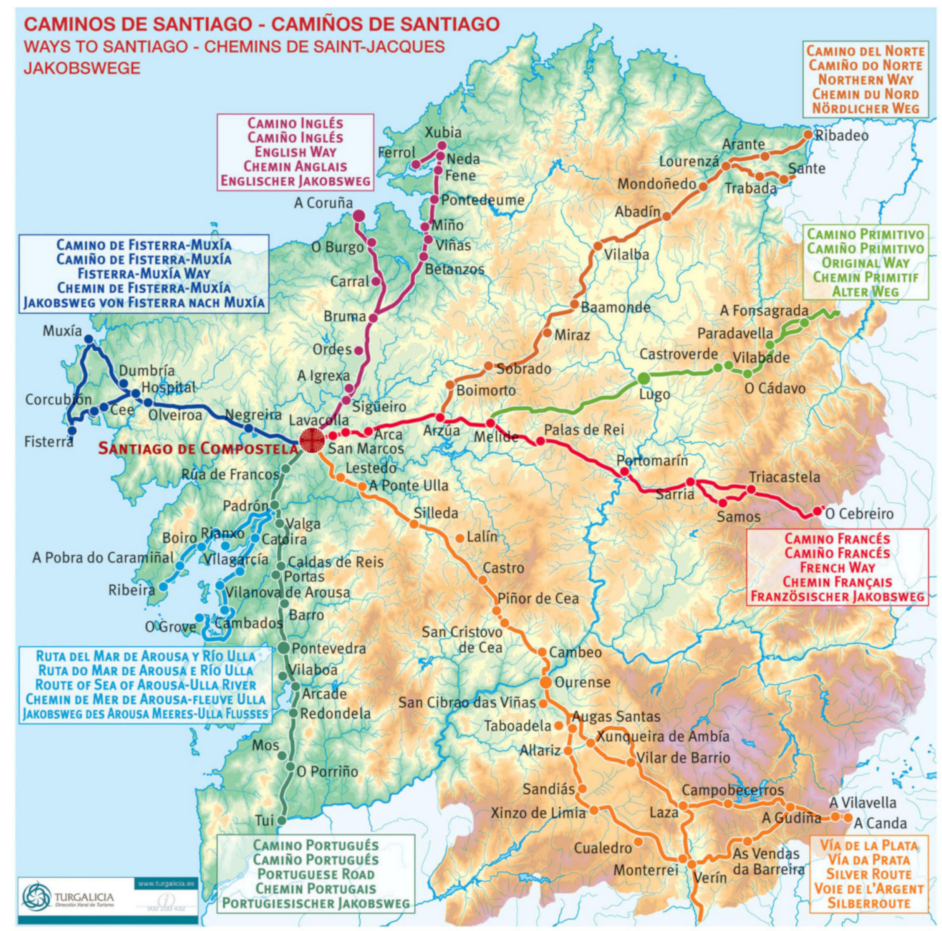

Figure 1. The Routes of Santiago de Compostela in the region of Galicia (Spain). Source: Turismo.gal. https://www.turismo.gal/docs/mdaw/mdk4/ edisp/turga098257.pdf?langId=es_ES (accessed on 24 July 2021).

The Route of Santiago has steady traffic throughout the year, which intensifies during the summertime when the weather is milder and people in the northern hemisphere are on holiday. In addition, visitor arrivals increase during the celebration of the Xacobeo Holy Year (Jacobean year or Jubilee year), when the festivity of the Saint (25 July) falls on a Sunday and pilgrims who visit the tomb of the Apostle in the Cathedral of Santiago de Compostela are granted "plenary indulgence," in other words, they are forgiven for their sins. Furthermore, throughout the Xacobeo, various cultural events are held, ranging from educational and academic activities, conferences, art exhibitions, and concerts to gastronomic happenings [12]. Due to the exceptional situation caused by the pandemic, the Pope has decreed an extension of the celebrations of the 2021 Xacobeo Holy Year until 31 December 2022, which is good news for pilgrims and businesses alike.

\subsection{Background and Current Situation of Tourism on the Route of Santiago}

Tourism on the Route of Santiago has a considerable impact on both the economy and the society, not only in Santiago de Compostela but also in the whole of Galicia since the promotion of the pilgrimage route as a tourist attraction has prompted an exponential increase in international and national tourism arrivals in the 21st century [13]. Lopez, Pazos-Otón, and Piñeiro-Antelo [14] claimed that the intense tourist promotion conducted from 1993 has resulted in a continuous increase in the number of visitors, and most of them are pilgrims. The data of Compostelas (document collected at the Pilgrim's Reception Office in the Cathedral of Santiago de Compostela certifying that a pilgrim has completed the Camino de Santiago) issued by the Archdiocese of Santiago de Compostela support this point, as the number of pilgrims receiving the Compostela amounted to 327,378 in 2018, a significant increase from 1993 when 99,436 Compostelas were awarded [14].

It is also important to qualify the visitors arriving in Santiago de Compostela to understand the nature of tourism in the city. Following the definitions of the World Tourism Organization [15] and according to CETUR [16], 67.9\% are tourists (also called overnight visitors), as their trips include an overnight stay, whereas $32.1 \%$ of the visitors are excursionists or same-day visitors, in other words, they do not stay in the city overnight. 
As for the purpose of their visits, the largest proportion (48\%) visit Santiago for tourism and leisure, whereas $33.8 \%$ refer to the pilgrimage as the main purpose of the trip. Visitors in CETUR's study stated as their preferred tourist attractions the Cathedral of Santiago de Compostela and its surrounding area $(84.2 \%)$, the Route of Santiago $(53.5 \%)$, and the Old Town or historic center $(46.5 \%)$.

The increase in visitor arrivals has not always been considered in a positive light. For example, the current Strategic Tourism Plan for Santiago 2017-2022 [17] highlights the possible loss of identity caused by the development of a fast food and souvenir model that homogenizes the tourist experience. Moreover, some problems have arisen from the interaction between the tourist activity and the local population: unstable low-quality employment, progressive abandonment of the Old Town due to the lack of essential services for prospective residents (optic fiber, elevators in older buildings, or parking, amongst others), overcrowding in the main tourist areas, and real estate speculation when residential housing is destined for tourist and non-residential uses [17]. All of these are consistent with the gentrification trends that can be observed (although not exclusively) in other Spanish and European cities, where depressed neighborhoods are rebuilt to attract more affluent inhabitants and investors, that end up displacing the original neighbors. Although tourism has contributed to gentrification to a certain extent, it is not the only one to blame. On the other hand, a process associated with tourism is "crowding out" [3], which occurs when local populations are displaced and economic activities are pushed away from city centers, which become a "theme park" for tourists. Buildings are preserved on the outside, while on the inside, short-term apartment rentals, souvenir shops, and restaurants can be found. Although Santiago de Compostela is still far away from Barcelona or Madrid in this respect, the concern for overtourism is already in the social, political, and academic debate.

\subsection{The Role of the Local Community in Tourism}

Despite the problems and negative impacts that tourism can have on the local community, these can be overcome if the benefits it brings about are effectively handled. In other words, tourism can help to solve urban and social problems, diversify the economy, and favor social equality in the region [18] when its development and management are conducted in a well-planned manner through the implementation of suitable policies that benefit both visitors and the local community. This substantiates the need to develop and use innovative methodological approaches in the generation of local and regional tourism policies by carrying out a preliminary analysis of the power dynamics that underpin the relationship between the local community and visitors in the tourist destination and ensuring that the needs of all stakeholders are met. Our study aimed to identify the local community's perceptions and suggest ways in which political leaders and decision makers can integrate them as an essential part of local development.

Nearly two decades ago, Mowforth and Munt [19] (p. 237) pointed out the importance of developing sustainable tourism through the involvement of the local community, drawing attention to "the implication that there is a willingness on the part of those who receive guests and possibly even an assumption that they have a degree of control over tourist developments in their community." Meanwhile, according to Rasoolimanesh, Ringle, Jaafar, and Ramayah [20], involvement in the tourism development process can improve residents' awareness of its benefits and costs, subsequently influencing their support for tourism development. In this line, Jaafar, Rasoolimanesh, and Lonik [21] contend that residents' perceptions of the impacts of tourism constitute a factor that is capable of influencing their behavior in favor of supporting tourism development in their communities.

In addition to identifying the perceptions of residents, it is essential to recognize and accompany their attitudes about policies that are geared toward tourism development to include them in tourist projects so that tourist planners can identify opportunities to be tackled or assess problems to be solved [22,23]. Likewise, concern for tourist behavior may be a limiting factor in tourism development; therefore, fostering a positive attitude may encourage its development. In summary, the community's attitude is fundamental in the 
development of sustainable tourism, which is why understanding and recognizing it can be a valuable tool for the elaboration of sustainable tourism projects.

It is often said that perceptions shape reality. Telfer and Sharpley [24] and Sharpley [25] posit that resident behavior will be different if more positive than negative impacts are perceived. In the first case, residents will be more receptive to supporting the development of tourist activities if tourism is expected to generate more benefits than costs for the area [26]. In contrast, they will be reluctant to participate if they perceive that the activity negatively impacts the destination. In their studies on the use of historic and cultural heritage sites in tourism, Gabriel, Soares, and Godoi [27] identified differences in the perceptions of tourism between individuals residing in tourist destinations with high tourist flows and those residing in destinations with lower tourist flows. The authors also concluded that residents of mature destinations do not perceive the impact of tourism (benefits or costs) the same way as residents of destinations in other life cycle stages.

Moreover, residents react differently to the same stimuli. Thus, whereas a part of the local community pays attention to the positive effects of tourism, such as economic opportunities, social integration, quality of life improvements, increase in the number of attractions, infrastructure, and services, other members of the same community may focus on its collateral effects and its ability to produce a series of disturbances, such as environmental and water pollution or social and cultural disruptions. Nevertheless, despite this duality and whatever the case, the local community should be considered as one of the most critical stakeholders in any project since, on the one hand, it will be positively or negatively affected by tourism planning and development [28], while on the other hand, it will play a vital role on shaping visitors' impressions and experiences.

\section{Research Methods and Objectives}

The overarching objective of this article is to present the results of a study that aimed to analyze the relationship between the perceptions of residents in Galicia toward tourism on the Route of Santiago and their interest in the development of this activity. The empirical study was carried out in the early months of 2021, at the beginning of the Xacobeo Holy Year, based on a questionnaire (see Appendix A) sent to residents of the seven major cities of Galicia that are in the itinerary of the Route of Santiago: Vigo, A Coruña, Lugo, Ourense, Pontevedra, Ferrol, and Santiago de Compostela. The map in Figure 2 shows the locations of these seven cities in the map of Galicia, as well as the Region of Galicia in Spain, Europe, and the world.

The survey was used to achieve the following three goals: (1) identify the perceptions of individuals living in the seven main cities in Galicia regarding the impact of tourism on the Route of Santiago; (2) identify their intention to participate in the development of tourism on the Route of Santiago; (3) analyze if there are any significant differences in their perceptions of tourism.

Based on previous studies [20,29-35], a Likert scale with five points, ranging from 1 ("strongly disagree") to 5 ("strongly agree"), was used to measure some of the items in the questionnaire (Appendix A), which was divided into three parts. The first part consisted of a series of questions about respondents' perceptions of the impacts of tourism; the second part enquired about the respondents' intentions to support tourism in their cities, as well as on the Route of Santiago in general; and the third part was intended to collect demographic data (sex, age, marital status, education, neighborhood of residence).

A non-probabilistic sampling technique called snowball sampling was used in order to reach the highest number of responses. The data collection phase took place between 1 February 2021 and 10 April 2021. As a result, a total of 958 questionnaires were answered in our survey, although 159 were discarded because the respondents did not comply with the basic requirements to participate in the sample: either living or working in one of the seven largest Galician cities on the Route of Santiago. In any case, with the remaining 799 responses, a 95\% confidence level and a $4 \%$ margin of error were maintained. A summary of the data discussed in this paragraph is presented in Table 1. 


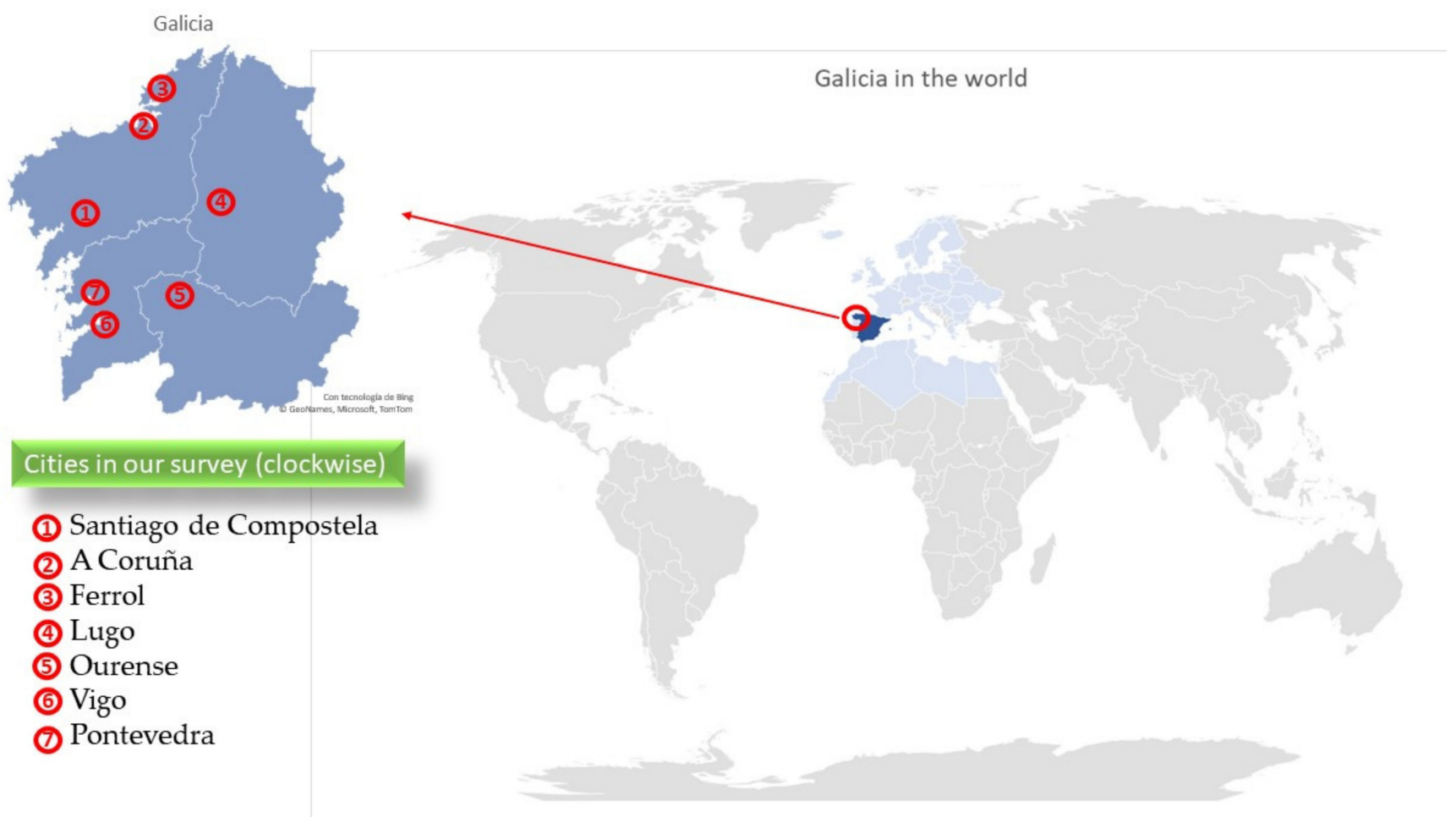

Figure 2. Maps with the location of Galicia and the seven cities in our survey. Source: Own elaboration using Excel.

Table 1. Survey specifications.

\begin{tabular}{|c|c|}
\hline Population sample & $\begin{array}{c}\text { Residents of the seven major cities of Galicia that were in the } \\
\text { itinerary of the Route of Santiago }\end{array}$ \\
\hline Geographic area & $\begin{array}{c}\text { Vigo, A Coruña, Lugo, Ourense, Pontevedra, Ferrol, and } \\
\text { Santiago de Compostela }\end{array}$ \\
\hline Sampling procedure & $\begin{array}{c}\text { Snowball sampling } \\
\text { Online }\end{array}$ \\
\hline Survey period & 1 February 2021-10 April 2021 \\
\hline Total answered questionnaires & 958 \\
\hline Total valid questionnaires & 799 \\
\hline Confidence level & $95 \%$ \\
\hline
\end{tabular}

Source: Own elaboration.

The snowball sampling methodology is considered suitable for this kind of research because, besides proving more effective, the survey was carried out online and $85.6 \%$ of the population of Galicia has access to the Internet (OSIMGA, 2019). Thus, our population sample was bigger than the samples of other studies on the perception of the impacts of tourism: 400 respondents in Faulkner and Tideswell's study [36], 415 respondents in Williams and Lawson's [29], 352 in Mcdowall and Choi's [37], and 400 valid responses in Vareiro, Remoaldo, and Cadima's [38].

Once the data were collected and invalid answers were sorted out, a descriptive statistical analysis using SPSS (version 24.0) was performed to identify the perceived impact of tourism in the seven cities mentioned above. We also studied the averages for each city to identify possible differences in the perception of individuals living in different stages along the Route of Santiago. In the following section, the results of our survey are presented and discussed.

\section{Presentation and Discussion of the Results}

As shown in Figure 3 (study sample by city), most of the responses were collected in the city of A Coruña (almost $40 \%$ of the total), followed by the city of Ferrol with about $26 \%$ and Santiago de Compostela with almost $14 \%$ of the answers. Ourense and Pontevedra 
were the cities where fewer responses were received: $1.5 \%$ and $3 \%$, respectively. The scarce number of responses generated a limitation in the study since the statistical analyses for these two cities were not significant owing to the low response level. In between the two extremes, $6 \%$ of the responses corresponded to the city of Vigo, whereas $11,4 \%$ of the population sample came from the city of Lugo.

\section{Pontevedra Ourense}

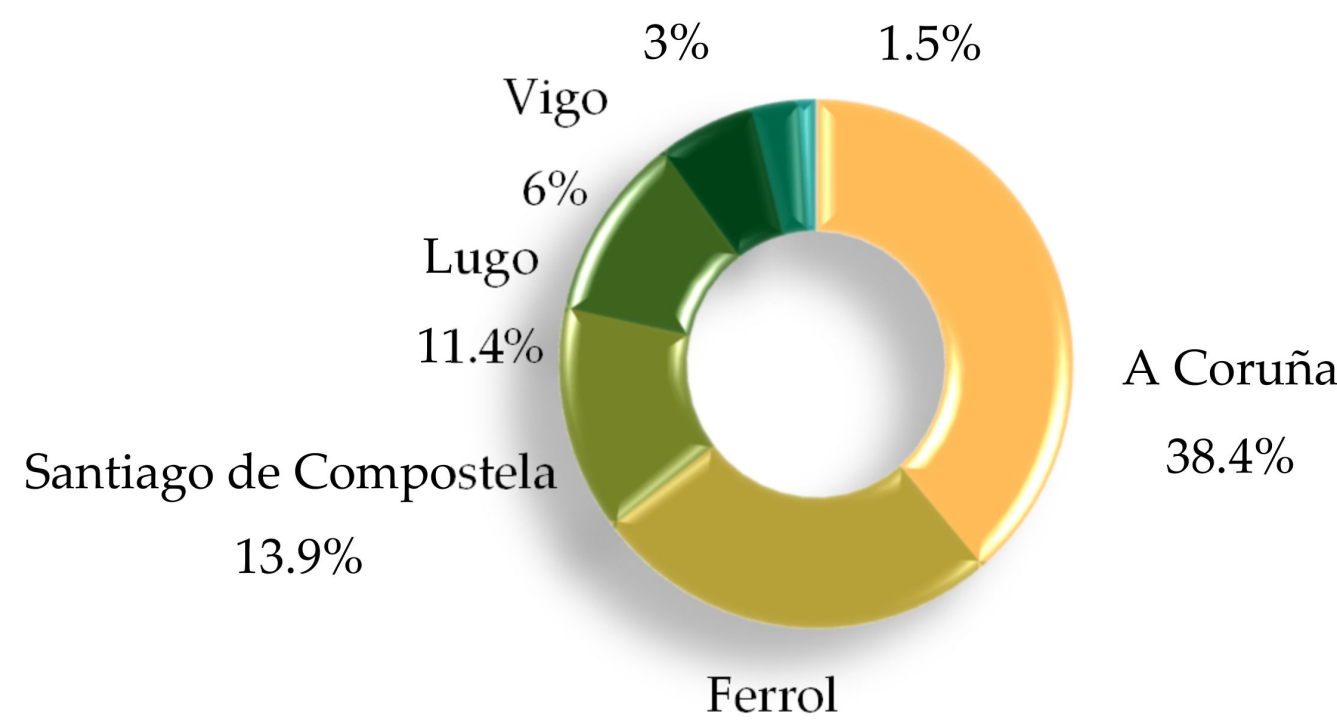

$25.8 \%$

Figure 3. Study sample by city. Source: Own elaboration.

\subsection{Demographic Profile}

In demographic terms, as can be seen in Figure 4, more than half (65\%) of the respondents were women; they showed a particular interest in participating in or at least getting to know about our tourism-related research. Furthermore, the most significant age group in the sample was Generation Y or millennials, who are individuals born between 1980 and 2000, which accounted for more than half of the respondents (54.6\%), followed by Generation X (26.2\%), who are individuals born between 1965 and the late 1970s. Generation $Z$, i.e., young people under 18, was less represented (under $4 \%$ ). Therefore, the sample was mainly composed of an adult population. Moreover, many respondents possessed a high level of education, as can be inferred from the fact that $70 \%$ of them had completed undergraduate or postgraduate university studies.

As for their employment status, the sample was formed chiefly by working people (almost $60 \%$ ) who were employed by public administrations $(18 \%)$ or private companies (30\%) or were self-employed. The remaining $40 \%$ were either retired or unemployed, as was the case of many students in Santiago de Compostela, which hosts a public university. In addition, the sample was made up of people whose monthly family income was over 1501 EUR. This figure is consistent with the average salary in Galicia, which according to the last of Adecco's Salary Monitors available at the time of writing this article, was 1586 EUR per month in 2020, compared with the average for Spain, which stood at 1658 EUR per month, and for the average gross ordinary salary in the 28 countries of the European Union, which amounted to 2091 EUR per month [39]. Finally, an overwhelming majority of the respondents did not work in the tourism, travel, and hospitality sectors, with less than 30\% of the respondents doing so. 


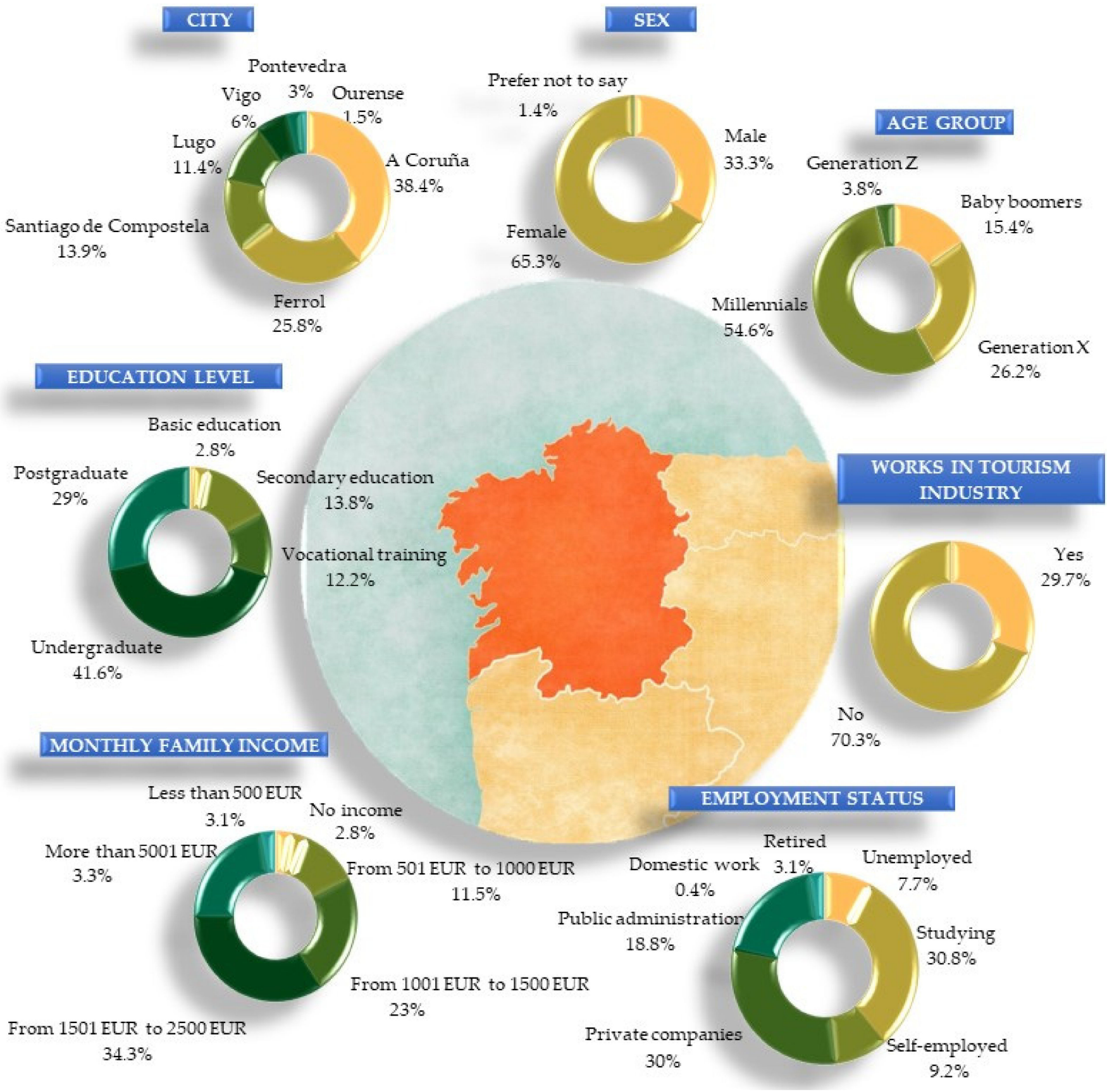

Figure 4. Demographic profile of the survey respondents. Source: Own elaboration.

\subsection{Perception of the Impacts of Tourism on the Route of Santiago}

Before presenting the results obtained in our analysis of the differences between the seven cities in more detail, we highlight some general data from the study.

Figure 5 shows the results for the 15 statements corresponding to the items about the perceived effects of tourism. For all the items, the Likert scale ranged from 1 ("strongly disagree") to 5 ("strongly agree"). Thus, the data revealed that, in general, the residents of the seven main Galician cities surveyed agreed that tourism on the Route of Santiago had a positive effect in their respective cities in particular and in the region of Galicia at large; meanwhile, respondents did not show particular concern about the negative impacts stated in the questionnaire, except for their fear that tourism on the Route of Santiago might contribute to a generalized price increase. 


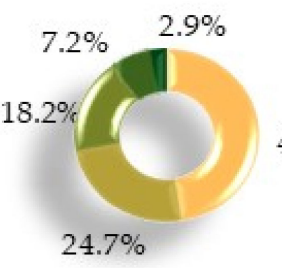

Tourism is good for the city

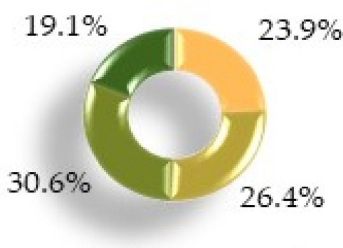

Tourism increases prices in town

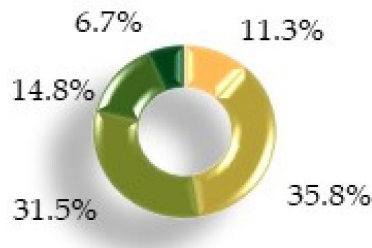

Tourism fosters the conservation and restauration of buildings

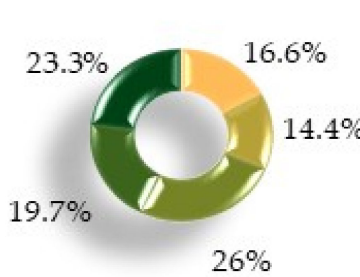

Tourism is good for me

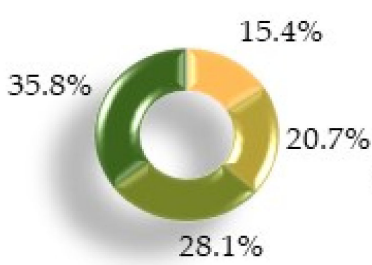

Tourism increases pollution in the city

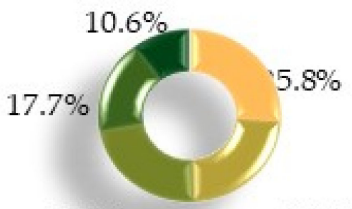

$22.9 \%$

Tourism contributes to the preservation of local values, customs and traditions

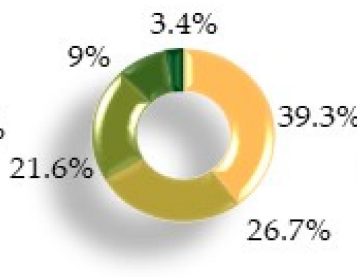

Tourism creates jobs for residents

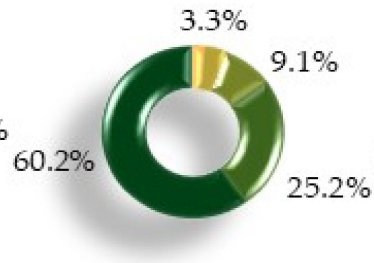

Tourism increases the city's crime rates

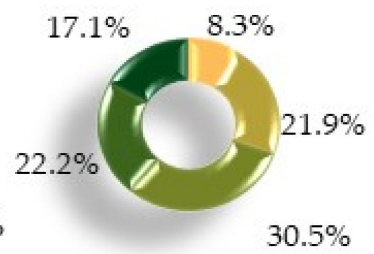

Tourism helps create new Tourism improves the

services for residents quality of life of residents

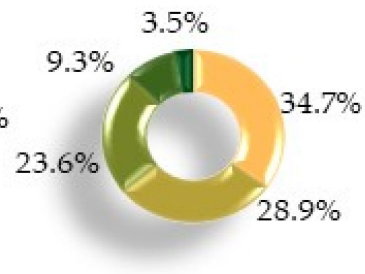

Tourism has a significant economicimpact

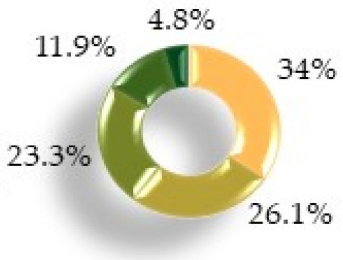

Tourism stimulates local culture and craftmanship

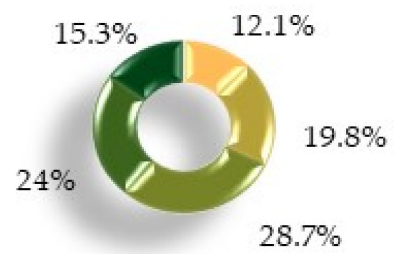

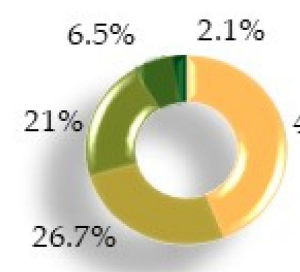

Tourism facilitates contact with people from different cultures

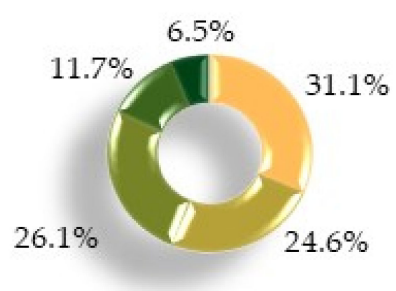

Tourism improves hospitality services in the city

Figure 5. Answers to the questionnaire (percentages related to a 5-point Likert scale) reflecting the local communities' perceptions of tourism on the Route of Santiago. Source: Own elaboration.

From the answers to the statement "Tourism is good for the city," we concluded that $71.7 \%$ of respondents expressed a positive opinion about tourism, agreeing that tourism on the Route of Santiago was good for their city. In contrast, only 10.1\% expressed disagreement with the statement. Furthermore, out of the 15 variables used, this statement was the one that obtained the highest average (3.98), which indicated that respondents to the survey recognized the economic importance of tourism for the region of Galicia.

Assessing the extreme averages for the benefits and costs of tourism on the Route of Santiago, we observed that the benefit that obtained the best results was the role of tourism as a driver in employment generation ("Tourism on the Route of Santiago creates jobs for residents"). In contrast, when the average for this item was low, it was an indicator that the local community did not perceive that tourism made a positive change. As a result, the benefit that was less valued by respondents was related to the statement "Tourism on the 
Route of Santiago improves the quality of life of the residents." As for the averages for the negative items (representing the costs of tourism), we identified that the cost that rated highest was that "Tourism on the Route of Santiago increases prices in town." In contrast, respondents did not perceive any correlation between tourism and the increase in crime rates in Galician cities.

When respondents were asked whether tourism generated benefits for them personally, this statement was the one with the lowest score amongst all the benefits of tourism. This led us to believe that, even without getting a direct benefit from tourism, our sample respondents understood that the economic activity that revolves around tourism is important for the inhabitants of Galicia, as can be inferred by analyzing the answers to two of the items "Tourism is good for the city" and "Tourism is good for me." Meanwhile the percentage of people who disagreed or strongly disagreed that tourism helped them personally was almost $43 \%$, while the percentage of respondents that agreed or strongly agreed that tourism was good for the city was much higher ( $71.7 \%$ of respondents). Therefore, we can conclude that the population sample perceives that tourism is an opportunity to improve the development of their cities and the region of Galicia at large, even though, at the same time, they do not perceive a personal gain from it.

After this initial presentation of the results for the whole of Galicia, we now proceed to present the perceptions of the effects of tourism in the cities surveyed, both positive and negative. First, however, it should be noted that out of the seven cities initially chosen, two of them (Ourense and Pontevedra) were not considered in the following comparisons because the number of answers collected from these cities was insufficient and, therefore, statistical analyses did not produce significant results with such a low level of responses.

\subsection{Positive Effects of Tourism}

First of all, it should be pointed out that of the 12 statements related to positive effects, there was a total agreement for only one of the statements: "Tourism on the Route of Santiago is beneficial for me." In other words, in all the cities surveyed, respondents agreed with that statement. Moreover, it is remarkable that out of the five cities with which comparisons could be made, Santiago de Compostela was the one that displayed a different perception about the benefits of tourism in five items.

Although there was a strong agreement with the statement "Tourism on the Route of Santiago generates employment for residents," Vigo was the city where respondents perceived that tourism had a lower power to generate employment. In contrast, the other four cities recognized that tourism had a very positive effect in this regard (Figure 6).

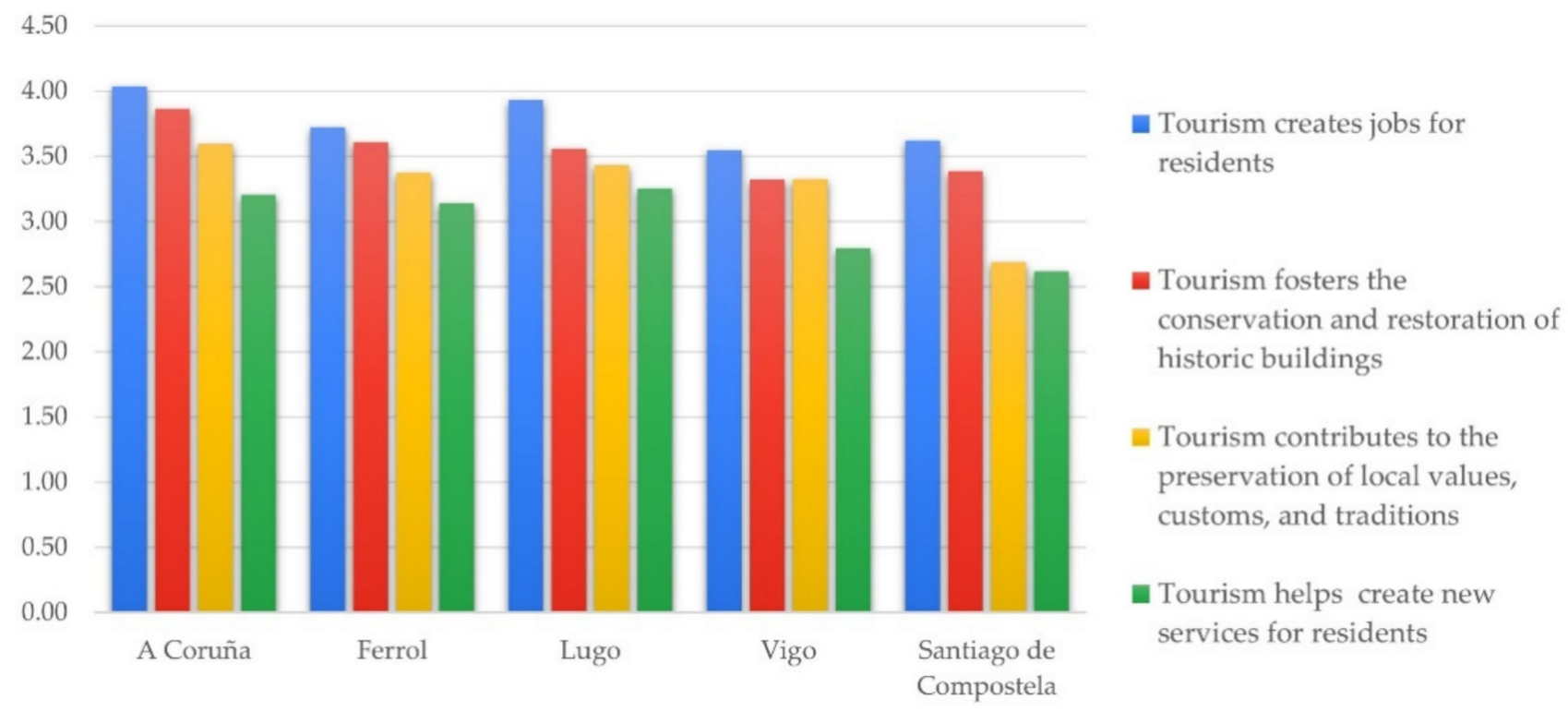

Figure 6. The benefits of tourism on the Route of Santiago I. Source: Own elaboration. 
As for cultural heritage, respondents from Santiago de Compostela agreed less with the statement "Tourism on the Route of Santiago contributes to preserving local values, customs, and traditions" than respondents from A Coruña, Ferrol, Lugo, and Vigo (Figure 6). Furthermore, A Coruña was the city with the strongest perception about the ability of tourism to bolster the conservation and restoration of historic buildings, in contrast to respondents from Santiago de Compostela, who were the most critical ones. The fact that Santiago is a UNESCO World Heritage site that receives more tourists than any of the other four cities may condition this perception.

Similarly, Santiago de Compostela was also the city where respondents agreed the least with the statement that "Tourism on the Route of Santiago helps to create new services for residents" (Figure 6).

The perception of Vigo's residents on the benefit of tourism derived from "the possibility of getting into contact with people from different cultures" was the lowest out of the five cities studied. In contrast, A Coruña was the Galician city where there was the strongest positive perception about the possibility of having contact with people from different cultures thanks to tourism. Meanwhile, when we only focused on significant differences, Vigo was found to be the most diverse of the five cities (Figure 7).

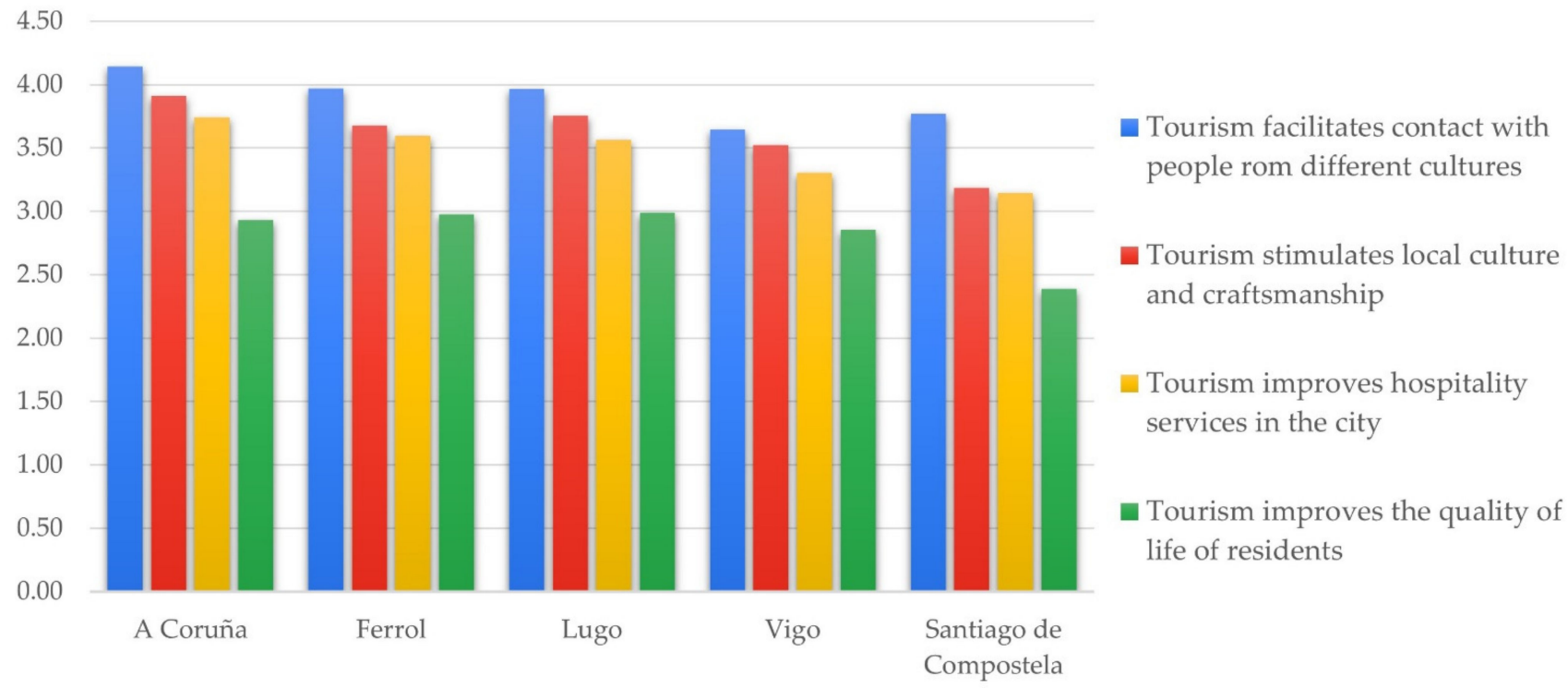

Figure 7. The benefits of tourism on the Route of Santiago II. Source: Own elaboration.

In contrast, when checking the results for the statement "Tourism on the Route of Santiago boosts the local culture and crafts," we found that for A Coruña, the result was just the opposite of that of the previous question (Figure 7). In other words, this statement shows that A Coruña was the city where the perception that tourism can improve the city's culture was the strongest. In contrast, Santiago de Compostela showed the weakest perception about the ability of the tourist activity to improve the city's cultural dimension.

Finally, Santiago de Compostela's residents were also the ones that agreed the least with the statements: "Tourism on the Route of Santiago improves hospitality services in town" and "Tourism on the Route of Santiago improves the residents' quality of life" (Figure 7). In other words, Santiago was the city where the average reached the lowest value. Moreover, this difference in the average of Santiago relative to the other cities was statistically significant. Santiago was followed by A Coruña in the first statement on the capacity of tourism to improve the city's hospitality services; meanwhile, for the second statement, which was related to tourism improving the quality of life in the city, Santiago was followed by Vigo in terms of perceiving this benefit of tourism in the most favorable light. Nevertheless, the difference between Vigo and Santiago might have been due to the number of tourists that each of the cities receives, i.e., the amount of visitors arriving in the 
city of Vigo is significantly lower than the number of visitors arriving in Santiago, which is the final destination and reason for this pilgrimage route.

As was already highlighted earlier, out of the 12 statements related to the positive effects, the only point where all respondents in the cities analyzed showed similar perceptions was for the statement "Tourism on the Route of Santiago is beneficial for me," from which it can be inferred that there was a generalized belief amongst respondents that they did not get any personal benefits from tourism. The highest score for that statement was 2.6. However, when asked if tourism on the Route of Santiago was beneficial for the city, respondents in the five cities agreed that it was, with the lowest average (3.53) in Santiago de Compostela. It should also be noted that Santiago's perceptions were statistically different from the perceptions of the other cities in our survey, whereas A Coruña and Ferrol were the cities where the benefits of tourism from the Route of Santiago were appreciated the most (Figure 8).

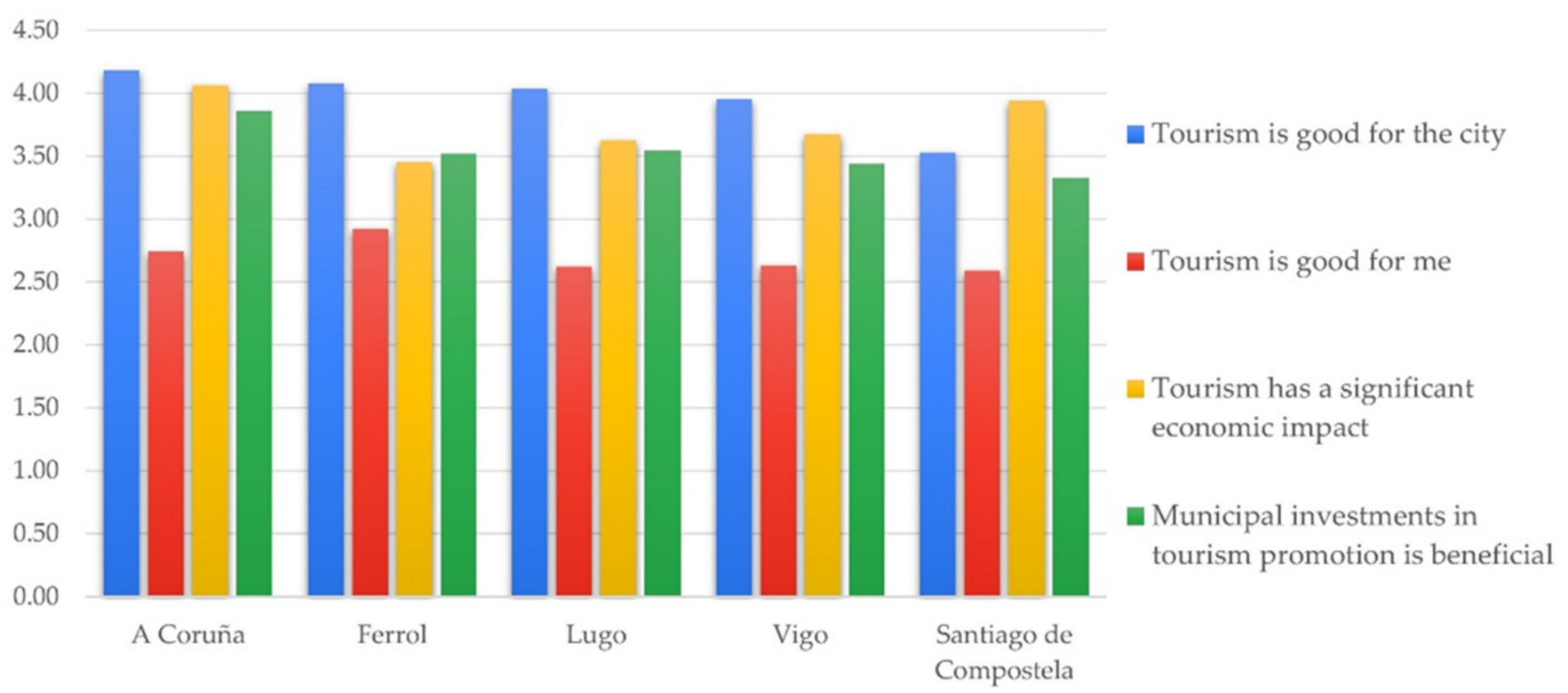

Figure 8. Benefits of fostering tourism development on the Route of Santiago. Source: Own elaboration.

The answers to the statement "Tourism on the Route of Santiago has a significant economic impact" turned out to be positive in the five cities, with averages above 3.25. However, for this statement, there was also a significant difference in the average obtained by the city of Ferrol in relation to the other four Galician cities. Specifically, Ferrol revealed a weaker perception of the economic impact stemming from tourism on the Route of Santiago (Figure 8).

Finally, the perception of residents of the Galician cities analyzed in this study about whether the municipal investment in tourism promotion is beneficial for the city was very positive. It is remarkable that in the city of A Coruna, the perception was primarily positive (Figure 8). In this respect, it is interesting to note that the sample in this study supported the investment made by local governments to promote tourism on the Camino de Santiago. This is a significant aspect because promotion policies are seen as an investment rather than as an expenditure. As far as they are considered an investment, they are expected to generate a return to the local community, such as creating jobs and income, improving infrastructures, or promoting contact with people from different cultures, amongst the other benefits of tourism presented in this article.

\subsection{Perceptions of the Negative Effects of Tourism}

Regarding the perception of the costs generated by tourism, the most remarkable negative effect perceived by the respondents was the increase of prices in their cities as a 
byproduct of tourist activity. Although this was the dimension that obtained the highest average in the five cities, the residents of Santiago de Compostela were the ones that displayed the highest average, showing a statistically significant contrast with the results obtained for the rest of the cities surveyed, where the costs of tourism were perceived in a similar way (Figure 9).

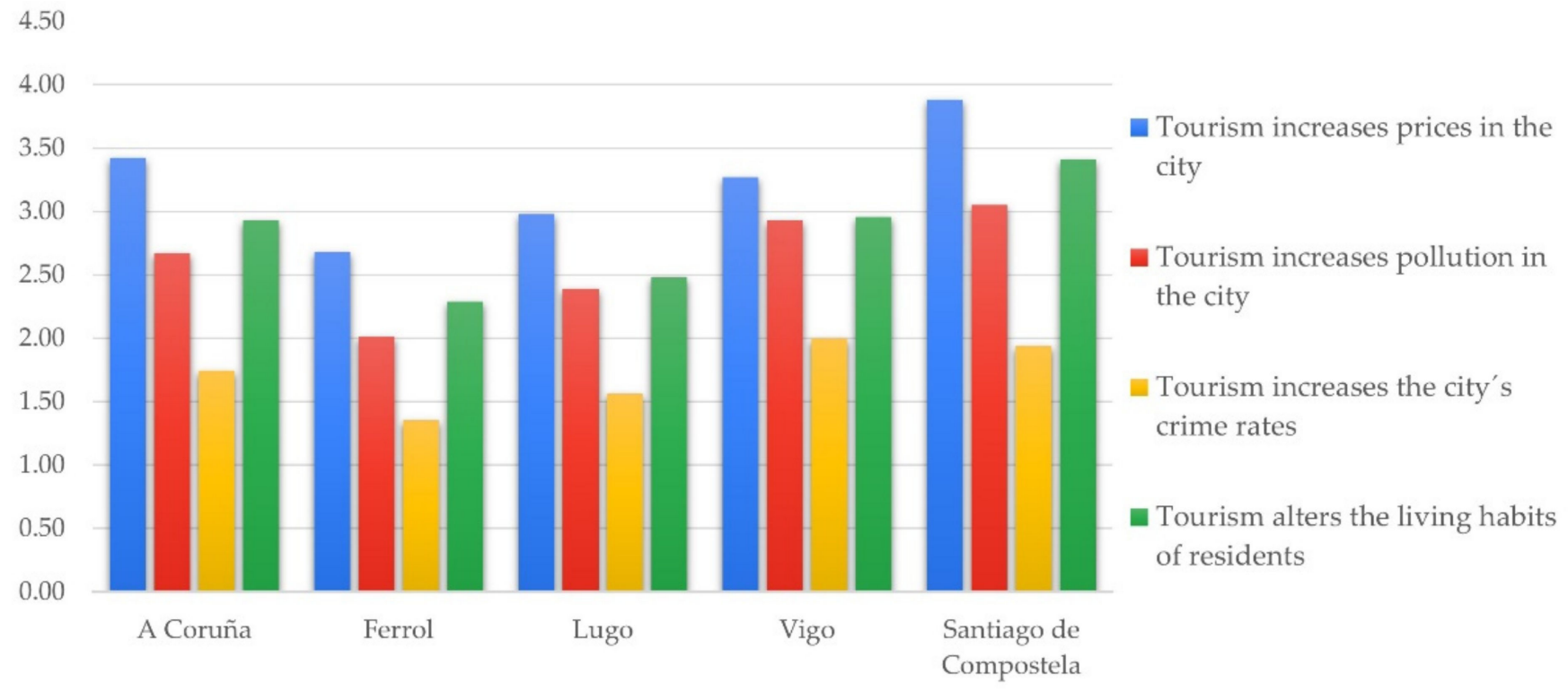

Figure 9. The costs of tourism on the Route of Santiago. Source: Own elaboration.

As for the three other negative impacts analyzed in this research ("Tourism on the Route of Santiago increases pollution in town," "Tourism on the Route of Santiago increases crime in the town," and "Tourism on the Route of Santiago alters the habits of life of the residents"), the respondents from the city of Ferrol displayed a statistically significant difference in their perception relative to the other four cities (Figure 9). For these three statements, Ferrol's respondents were the ones who agreed the least with the negative impact of those factors. On the other hand, Santiago de Compostela had the highest averages for these three costs generated by the tourist activity.

Finally, once the perceptions of the impact of tourism on the Route of Santiago in the main cities of Galicia (benefits and costs of this activity) are known, we can conclude that respondents were conscious that this socio-economic activity generated more benefits than costs for the region. In the following section, we present the second part of the study, which sought to assess the interest of the local communities in getting involved in the development of tourism in the region.

\subsection{Local Communities' Willingness to Get Involved in Tourism}

After the first part of the questionnaire about the perceptions of the positive and negative effects of tourism on the Pilgrims' Route to Santiago, a question was introduced to inquire about the locals' interest to help develop tourism by asking whether they would be willing to contribute to tourism development and suggesting ten possible ways in which they could cooperate (Appendix A). Specifically, the question was: "If you had the opportunity, would you be willing to collaborate in the development of tourism in your city?" Only $12.4 \%$ of the respondents in the sample indicated that they had no interest in helping to develop tourism in the region. On the other hand, almost $90 \%$ of the sample was interested in carrying out some kind of activity to help develop tourism on the Route of Santiago (Figure 10). 
If you had the opportunity, would you be willing to collaborate in the development of tourism in your city?
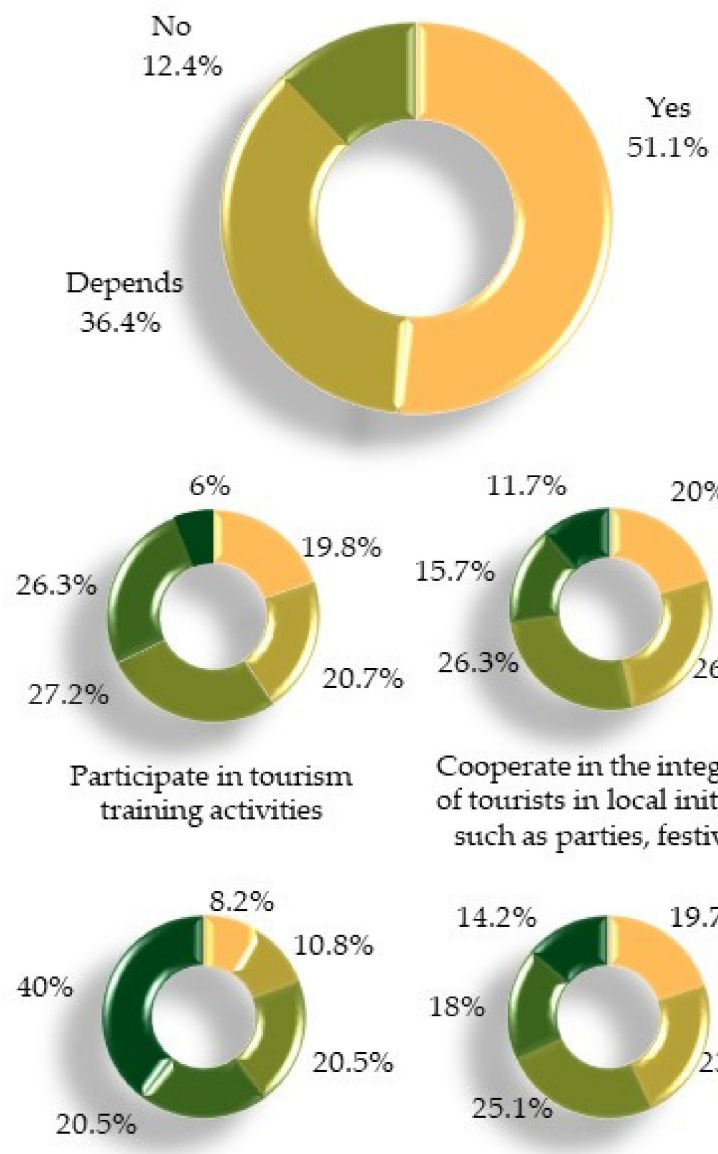

Invite tourists to participate in my daily activities

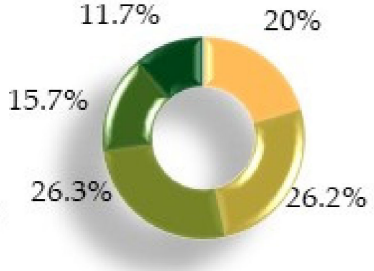

Cooperate in the integration of tourists in local initiatives such as parties, festivals...

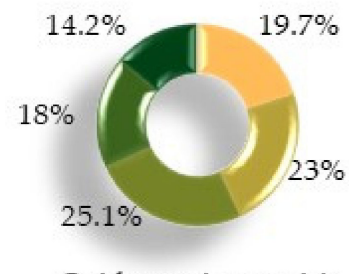

Guide tourists to visit points of interest in the city
If your answer to the previous question was "yes", how likely would you be willing to collaborate in the following activities? ( 1 is never and 5 very frequently)
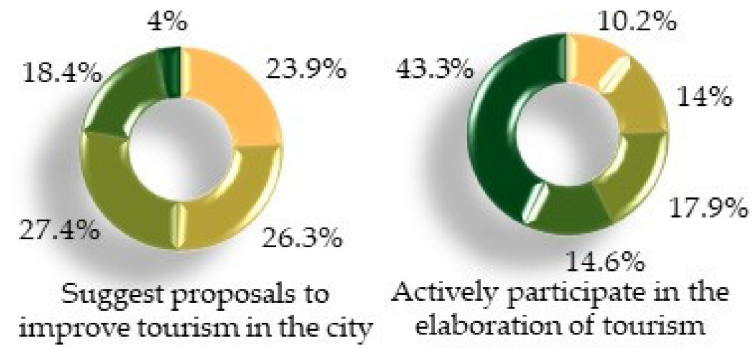

Actively participate in the elaboration of tourism

planning proposals
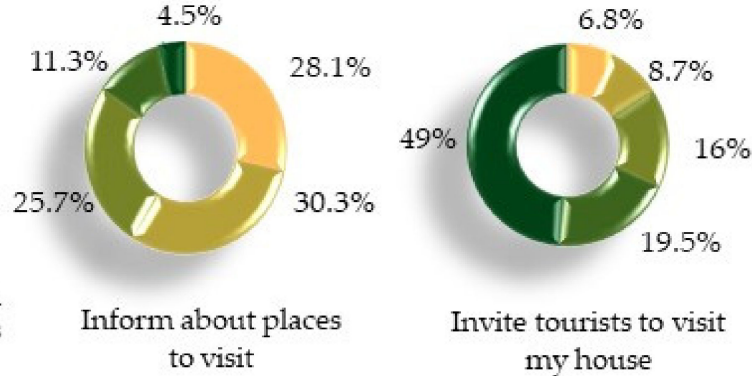

Invite tourists to visit my house
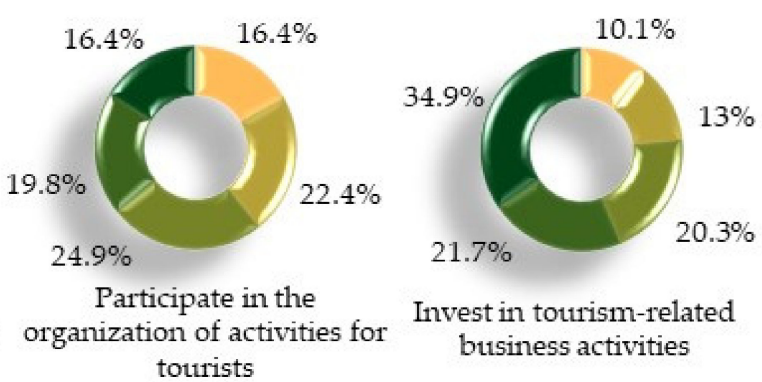

Invest in tourism-related business activities

Figure 10. Local populations' interest in collaborating in tourism development activities. Source: own elaboration.

Amongst the ten statements related to the activities they would be willing to carry out to contribute to the development of tourism in Galicia, the highest averages were obtained for the statements: "Inform about the places to visit" and "Suggest proposals to improve the tourism in the city." As such, we identified that people living in Galicia, on the one hand, valued the visitor's experience since they were willing to help by getting in direct contact with visitors in order to offer information about places to visit. Nevertheless, on the other hand, they were also willing to participate in tourism management by contributing their proposals to improve this activity (Figure 11).

The lowest average was the one related to the statement that enquired about respondents' willingness to "Invite tourists to visit my (their) house," followed by "Invest in tourism-related businesses." Thus, even though the effects of tourism on the Pilgrims' Route to Santiago were seen in a positive light and taking into account that one of the benefits that obtained the best scores was that tourism on the Route allowed contact with people from different cultures, we can appreciate that there are certain limits to the relationship with tourists and visitors as respondents were not interested in inviting tourists to visit their homes. 


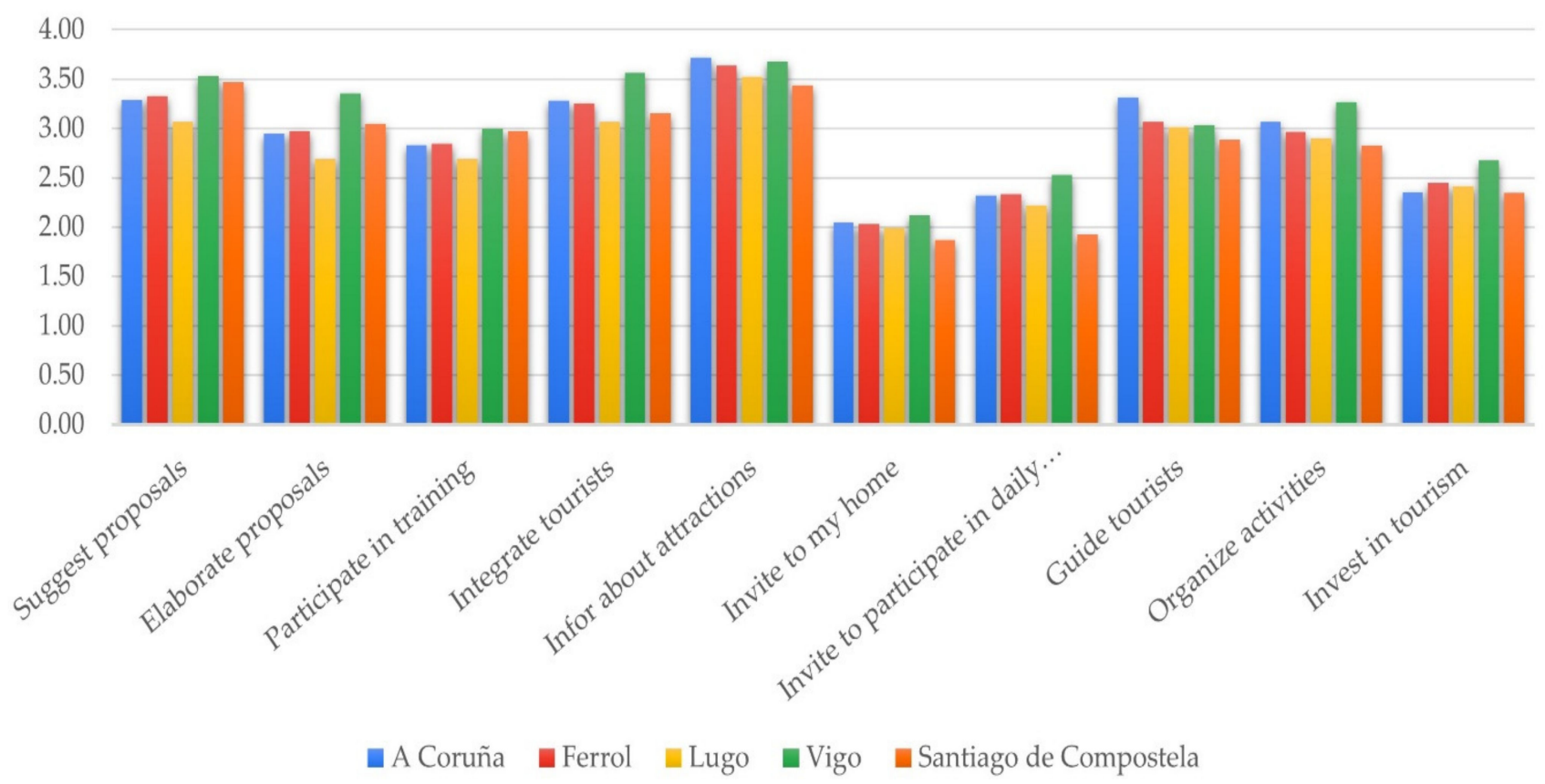

Figure 11. Local populations' interest in getting involved in the development of tourism on the Route of Santiago. Source: Own elaboration.

On the other hand, regarding the second-lowest average, namely, the one related to investing in tourism-related businesses, this result also shows that even though tourism is an essential economic activity for the region with a significant economic impact on the area, respondents were not considering investing in tourism. This was a noteworthy remark in the survey, as it shows that tourism in itself is an activity that was well-considered by residents, although financially, they did not depend on it.

After carrying out our study, we performed an ANOVA test whose results can be found in Appendix B. Our aim was to verify if there are any differences in the perceptions of respondents in the cities surveyed. The ANOVA test was carried out in three steps: firstly, the data bank was adjusted to convert textual variables in numerical ones; secondly, the normality of the sample was verified, and, thirdly, the ANOVA test was carried out on one of the items. In the second step, the independent variables were checked for normal distribution using the Shapiro-Wilk test, observing that the significance for all 10 variables is less than 0.05 . This indicates that the sample distribution is not normal, even though the normality of the residuals is a prerequisite for ANOVA. However, since the sample is relatively large (650 cases), even with non-normal data results, the data are robust enough to proceed with the analysis. In the third step, the place of residence was used as dependent variable taking the values 0 to 4 (A Coruña $=0$; Ferrol $=1$; Lugo $=2$; Santiago de Compostela $=3$; Vigo $=4)$ and the independent variables used were the 10 items in our questionnaire stating tourism-related activities residents would be willing to take part in to test of homogeneity of variances (Levene's Statistics). Only one of the items turned out to be inconsistent, whereas the 9 remaining variables display a homogenous variance.

In the ANOVA analysis, only for one of the 10 variables ("I am willing to guide tourists to visit points of interest in the city") the significance obtained a value equal to 0.49 , which demonstrates to be marginal, to the limit of significance for this test. Therefore, it can be inferred that there are no differences amongst the averages of the groups identified for the five cities.

As a result, we found out that there were no significant differences between the perceptions in the five cities surveyed: A Coruña, Ferrol, Santiago de Compostela, Vigo, and Lugo. Thus, it can be asserted that the population in the study sample that responded that they were willing to collaborate in the tourism development behaved in the same way. 
In conclusion, considering the host community's interest in getting involved in the development of tourism on the Route to Santiago, it would be helpful to maximize the perception of the positive benefits while minimizing the negative impacts. Therefore, policy and decision makers that are responsible for tourism development in the region (councils, central government delegations in each of the four provinces, Xunta de Galicia) should involve civil society organizations in the local communities (neighborhood associations, friends of the Route, and others) in the tourism policy decision-making process. Their opinions should be taken into account in local tourism planning as a legitimate opinion source that could help to shape decision making.

\section{Conclusions}

This article addresses an underdeveloped topic in tourism planning and management, which is the role that local communities play in shaping the tourist experience at the destination. Traditional tourism planning has focused more on quantity than on quality, and on the industry's interests more than on those of visitors and residents. Instead of being ignored, local communities should be considered strategic collaborators in tourism planning and development since they are the ones that will experience first-hand the benefits and costs of tourism. Moreover, in our experience economy, local communities play a central role in creating a welcoming atmosphere for visitors, one that makes their stay at the destination unique, unforgettable, and worth sharing online.

The recent debate on the future of tourism after the pandemic revolves mostly around economic recovery, although the focus has slightly shifted to the environmental effects of tourism. Little attention is still paid to collateral social effects, such as overtourism. The role of local communities still occupies a secondary place, even though to make a real change, tourism planners and decision makers should consider involving the local community in the various stages of tourism development: first, in the decision-making phase, residents' inputs should be incorporated into strategies and action plans; second, in the development phase when proposals are tested; and, finally, in the implementation phase when visitors arrive at the destination and their interaction with locals shapes their mutual experiences and perceptions.

This article has conveyed the results of a research project that sought to address a topic that has received scant attention by identifying the perceptions of the positive and negative effects of tourism on the Route of Santiago of people living in the Spanish region of Galicia. In addition, it also sought to assess local host communities' interest in participating in actions that would contribute to the development of tourism in their city.

An online questionnaire (Appendix A) was sent to residents of the seven major Galician cities along the Route of Santiago. The answers were collected over two and a half months between February and April 2021. The first question aimed to ensure that respondents who did not live or work in any of the seven cities (A Coruña, Ferrol, Santiago de Compostela, Ourense, Vigo, Pontevedra, and Lugo) did not continue responding to the questionnaire. As such, we could focus on measuring the perceptions of individuals within the study's scope: residents and workers from those cities.

Our comparison between the cities is a relevant theoretical contribution to the study of the positive and negative effects of tourism on a UNESCO World Heritage site. In this regard, it is noteworthy that these results are even more attractive due to the innovative approach of our research and the fact that the Route of Santiago is a UNESCO World Heritage site with unequal social and economic effects in cities along the Route within the region of Galicia. This is the reason why the local population in different cities along the Route of Santiago had different perceptions of the importance of tourism, even though the tourist attraction in the background was the same for all of them.

One of our contributions to the study of the effects of tourism on the local population was the questionnaire that our research group created in order to carry out this study (Appendix A). The questionnaire could be used to survey local populations' perceptions 
and interest in participating in tourism development in other UNESCO World Heritage sites, as well as in other regions and cities.

As for the practical contributions of this study, we would like to underline the suggestion that the authorities responsible for tourism planning and management offer the local community the opportunity to get involved in the tourism decision-making process. Local communities' participation would help all stakeholders to maximize the positive effects of tourism for the host community while minimizing its costs. Moreover, by improving the relationship between host communities and tourism activities, the attitude toward tourists and visitors would also improve, strengthening the overall sense of hospitality in the destination.

Since its emergence in the 1970s, the concept of participatory development has taken a variety of forms, and in today's context, it is more important than ever before as a way of involving local societies in realizing sustainable development coupled with social justice, seeking to bridge the gap between regions, income levels, and gender. At present, information and communication technologies (ICTs) facilitate citizen participation in shaping public policies and administration by making it possible for citizens to communicate directly with governing authorities. The design and implementation of public policies in general, and in tourism in particular, involves listening to local communities; therefore, using technological advances to amplify the voices of the citizens contributes to this end.

ICTs in the field of tourism can provide low-cost solutions to share information and interconnect local communities with their public authorities, which would give citizens the chance to let their opinions be heard and give authorities the opportunity to respond to citizens' needs and demands. Nowadays, citizen participation in political decision-making is a priority, not only in the EU but also elsewhere, as it generates more possibilities to improve the citizens' quality of life while increasing accountability in political processes by making them more transparent.

Nevertheless, despite the availability of innovative ICT tools that could allow for a large number of people to express their opinions (e-participation), the part in which public authorities take them into account in public policy and legislation proposals is still missing. In other words, successful e-participation processes that enable citizens to take the initiative in making proposals and taking part in the discussion of issues that affect them (citizen empowerment) are still pending subjects in most administrations.

The field of tourism is no exception, as increased research and development of pilot projects that allow for a higher level of citizen involvement are needed. Nevertheless, from our study, we concluded that the general perception of tourism in the region is positive and that tourism on the Route of Santiago is more beneficial than harmful for the local communities. Furthermore, the study also determined that the local communities in the cities surveyed were willing to undertake activities to contribute to the ongoing development of tourism in the region, which tourism authorities could carry out by putting participatory tourism development initiatives in place.

A limitation of the study was the inability to measure the perception of the effects of tourism on the Route to Santiago in Ourense and Pontevedra and the involvement intentions of the local host communities due to the low number of responses obtained in these two cities. However, we managed to obtain a significant sample: 799 valid responses (out of a total of 958 questionnaires). Nevertheless, this limitation did not allow us to compare the seven main Galician cities we set out to compare on our survey on tourism on the Route to Santiago. Therefore, we consider that in future studies, it would be convenient to collect answers to the same questionnaire in these two cities to improve the sample.

Finally, it is worth highlighting that this research was conducted at a time of crisis arising from the COVID-19 pandemic, which greatly affected the functioning of the tourism sector, which is one of the major economic engines of the region. In this sense, the positive results regarding the perception of tourism and the high rates regarding the intention of the local community to get involved in tourism development might have been overrated. Therefore, among the future lines of research, we would like to point out the need to 
continue researching this topic in the future to confirm whether the results still hold when the pandemic is over and its impacts do not condition individuals' responses.

Author Contributions: All authors were involved in the conceptualization, research, formal analysis, and writing. All authors contributed to the development of this paper. Review and editing were done by J.-R.-R.S. and M.-F.C.-C. All authors have read and agreed to the published version of the manuscript.

Funding: This research was partially funded by the Cátedra do Camiño de Santiago e das Peregrinacións.

Institutional Review Board Statement: Not applicable.

Informed Consent Statement: Not applicable.

Data Availability Statement: Not applicable.

Acknowledgments: The authors sincerely acknowledge the valuable support of the Cátedra do Camiño de Santiago e das Peregrinacións in carrying out this research project, and Jhordano Malacarne Bravim from the Instituto Federal de Rondônia and Universidade Federal do Paraná, Brazil. The authors also wish to thank all the people who answered the questionnaire in our survey, as well as those who helped disseminate it, allowing the research to reach all corners of Galicia. Finally, the authors are grateful to the two anonymous reviewers for their constructive comments.

Conflicts of Interest: The authors declare no conflict of interest. The Cátedra do Camiño de Santiago e das Peregrinacións had no role in the design of the study; in the collection, analyses, or interpretation of data; in the writing of the manuscript; or in the decision to publish the results.

\section{Appendix A}

Questionnaire on local communities' participation in tourism development.

1. Where do you live?

A Courña

Lugo

Santiago

Ferrol

Pontevedra

Vigo

Ourense

Other

2. If you answered other, where?

3. In which neighborhood do you live?

4. Do you work or have you worked in any of the following activities?

Hotel, hostel, camping

Airbnb, tourist appartment

Transportation company (car rental, taxi, bus, train..)

Restaurant, café, pub, bar, club.

Travel agency, tourist information office, museum

Tourist guide

Souvenir shop, arts and crafts

Consulting

None of the above

5. Do you usually have contact with tourism

\begin{tabular}{|c|c|c|c|c|c|}
\hline & Never & Rarely & Occasionally & Sometimes & Very often \\
\hline at work & & & & & \\
\hline In my leisure time & & & & & \\
\hline
\end{tabular}


6. Contact with tourists alters my habits

\begin{tabular}{|c|c|c|c|c|c|}
\hline & Never & Rarely & Occasionally & Sometimes & Very often \\
\hline at work & & & & & \\
\hline In my leisure time & & & & & \\
\hline
\end{tabular}

7. In general, how would you qualify your contact with tourism?

(from 1 to 5 , being 1 the most negative and 5 the most positive)

8. How much do you agree with the following statements about tourism on the Route of Santiago? (from 1 strongly disagree to 5 strongly agree; if you have no opinion mark "no opinion").

\begin{tabular}{|c|c|c|c|c|c|}
\hline 1 & 2 & 3 & 4 & 5 & No opinion \\
\hline $\begin{array}{c}\text { Strongly } \\
\text { disagree }\end{array}$ & Disagree & $\begin{array}{c}\text { Neither agree } \\
\text { nor disagree }\end{array}$ & Agree & $\begin{array}{c}\text { Strongly } \\
\text { agree }\end{array}$ & \\
\hline
\end{tabular}

Tourism on the Route of Santiago ...

$\ldots$ is good for the city

$\ldots$ is good for me

... Creates jobs for residents

$\ldots$ increases prices in the city

... increases pollution in the city

... increases the city's crime rates

... fosters the conservation and restoration of historic buildings

... contributes to the preservation of local values, customs, and traditions

... helps to create new services for residents

... facilitates contact with people from different cultures

... stimulates local culture and craftsmanship

... improves hospitality services in the city

... improves the quality of life of residents

... has a significant economic impact

... Municipal investment in tourism promotion is beneficial

9. What is your opinion about the introduction of a tourist tax in the city?

It would improve the economic impact of tourism in the city

It would contribute to decentralize tourism in the city

It would be positive for the city

It would be positive for me

10. If you had the opportunity, would you be willing to collaborate in the development of tourism in your city? (Mark only one answer)

Yes

No

Maybe

11. If your answer to the previous question was "yes", how likely would you be willing to collaborate in the following activities? ( 1 is never and 5 very often)

\begin{tabular}{|c|c|c|c|c|}
\hline 1 & 2 & 3 & 4 & 5 \\
\hline Never & Rarely & Occasionally & Sometimes & Very often \\
\hline
\end{tabular}

Suggest proposals to improve tourism in the city.

Actively participate in the elaboration of tourism planning proposals.

Participate in tourism training activities

Cooperate in the integration of tourists in local initiatives such as parties, festivals ...

Inform about places to visit

Invite tourists to visit my house

Invite tourists to participate in my daily activities

Guide tourists to visit points of interest in the city

Participate in the organization of activities for tourists 
Invest in tourism-related business activities

12. Sex

Male

Female

Prefer not to say

13. Age

14. Study level

No studies

Primary education

Secondary education

Vocational training

Undergraduate

Postgraduate (Master, PhD)

15. Employment status

Unemployed

Private company

Public administration

Student

Self-employed

Domestic worker

Retired

Other

16. What is the average net income in your home?

Less than 500 EUR

From 501 EUR to 1000 EUR

From 1001 EUR to 1500 EUR

From 1501 EUR to 2500 EUR

From 2501 EUR to 5000 EUR

More than 5001 EUR

No income

\section{Appendix B}

Table A1. Results of the ANOVA test.

\begin{tabular}{|c|c|c|c|c|c|c|}
\hline & & Sum of Squares & df & Mean Square & $\mathbf{F}$ & Sig. \\
\hline \multirow{3}{*}{ Suggest proposals } & Between groups & 8.687 & 4 & 2.172 & 1.381 & 0.239 \\
\hline & Within groups & 1014.537 & 645 & 1.573 & & \\
\hline & Total & 1023.225 & 649 & & & \\
\hline \multirow{3}{*}{ Elaborate proposals } & Between groups & 11.685 & 4 & 2.921 & 1.796 & 0.128 \\
\hline & Within groups & 1049.109 & 645 & 1.627 & & \\
\hline & Total & 1060.794 & 649 & & & \\
\hline \multirow{3}{*}{ Participate in training } & Between groups & 4.178 & 4 & 1.044 & 0.566 & 0.687 \\
\hline & Within groups & 1189.816 & 645 & 1.845 & & \\
\hline & Total & 1193.994 & 649 & & & \\
\hline \multirow{3}{*}{ Integrate tourists } & Between groups & 7.01 & 4 & 1.752 & 1.082 & 0.365 \\
\hline & Within groups & 1045.097 & 645 & 1.62 & & \\
\hline & Total & 1052.106 & 649 & & & \\
\hline \multirow{3}{*}{ Inform about attractions } & Between groups & 6.531 & 4 & 1.633 & 1.273 & 0.279 \\
\hline & Within groups & 827.371 & 645 & 1.283 & & \\
\hline & Total & 833.902 & 649 & & & \\
\hline \multirow{3}{*}{ Invite to my home } & Between groups & 2.672 & 4 & 0.668 & 0.418 & 0.796 \\
\hline & Within groups & 1030.204 & 645 & 1.597 & & \\
\hline & Total & 1032.875 & 649 & & & \\
\hline
\end{tabular}


Table A1. Cont.

\begin{tabular}{|c|c|c|c|c|c|c|}
\hline & & Sum of Squares & df & Mean Square & $\mathbf{F}$ & Sig. \\
\hline \multirow{3}{*}{ Invite to participate in daily activities } & Between groups & 14.71 & 4 & 3.677 & 2.177 & 0.07 \\
\hline & Within groups & 1089.777 & 645 & 1.69 & & \\
\hline & Total & 1104.486 & 649 & & & \\
\hline \multirow{3}{*}{ Guide tourists } & Between groups & 16.6 & 4 & 4.15 & 2.397 & 0.049 \\
\hline & Within groups & 1116.544 & 645 & 1.731 & & \\
\hline & Total & 1133.145 & 649 & & & \\
\hline \multirow{3}{*}{ Organize activities } & Between groups & 7.19 & 4 & 1.797 & 1.053 & 0.379 \\
\hline & Within groups & 1100.755 & 645 & 1.707 & & \\
\hline & Total & 1107.945 & 649 & & & \\
\hline \multirow{3}{*}{ Invest in tourism } & Between groups & 3.786 & 4 & 0.946 & 0.523 & 0.719 \\
\hline & Within groups & 1166.801 & 645 & 1.809 & & \\
\hline & Total & 1170.586 & 649 & & & \\
\hline
\end{tabular}

\section{References}

1. UNWTO. "Overtourism"? Understanding and Managing Urban Tourism Growth beyond Perceptions—Executive Summary; UNWTO: Madrid, Spain, 2018. [CrossRef]

2. Koens, K.; Postma, A.; Papp, B. Is Overtourism Overused? Understanding the Impact of Tourism in a City Context. Sustainability 2018, 10, 4384. [CrossRef]

3. Camatti, N.; Bertocchi, D.; Carić, H.; Van Der Borg, J.; Camatti, N.; Bertocchi, D. A Digital Response System to Mitigate Overtourism. The Case of Dubrovnik. J. Travel Tour. Mark. 2020, 37, 887-901. [CrossRef]

4. Clemente-Suárez, V.J.; Navarro-Jiménez, E.; Moreno-Luna, L.; Saavedra-Serrano, M.C.; Jimenez, M.; Simón, J.A.; Tornero-Aguilera, J.F. The Impact of the Covid-19 Pandemic on Social, Health, and Economy. Sustainability 2021, 13, 6314. [CrossRef]

5. European Commission. The European Green Deal. Eur. Comm. 2019, 53, 24. Available online: https://eur-lex.europa.eu/legalcontent/EN/TXT/PDF/?uri=CELEX:52019DC0640\&from=EN (accessed on 24 July 2021). [CrossRef]

6. European Commission. Recovery and Resilience Facility. Available online: https://ec.europa.eu/info/business-economy-euro/ recovery-coronavirus / recovery-and-resilience-facility_en (accessed on 24 July 2021).

7. OECD. OECD Tourism Trends and Policies 2020. Spain. Available online: https://www.oecd-ilibrary.org/sites/8ed5145b-en/ index.html?itemId=/content/component/8ed5145b (accessed on 24 July 2021).

8. Gobierno de España. Plan de Recuperación, Transformación y Resiliencia. Available online: https://planderecuperacion.gob.es/ (accessed on 24 July 2021).

9. UNESCO World Heritage Centre. Spain's Properties Inscribed on the World Heritage List. Available online: https://whc.unesco. org/en/statesparties/es (accessed on 11 July 2021).

10. UNESCO World Heritage Centre. Santiago de Compostela (Old Town). Available online: https://whc.unesco.org/en/list/347 (accessed on 11 July 2021).

11. UNESCO World Heritage Centre. Routes of Santiago de Compostela: Camino Francés and Routes of Northern Spain. Available online: https: / whc.unesco.org/en/list/ 669 (accessed on 11 July 2021).

12. TURESPAÑA. The Xacobeo Holy Year: Reasons to Travel the Camino de Santiago, The Way of Saint James. Available online: https:/ / www.spain.info/en/discover-spain/xacobeo-camino-santiago/ (accessed on 11 July 2021).

13. Pereiro, X. Turismo y Peregrinación, Dos Caras de La Misma Moneda: El Camino Portugués Interior de Santiago de Compostela. Cuad. Tur. 2019, 43, 407-434. [CrossRef]

14. Lopez, L.; Pazos-Otón, M.; Pineiro Antelo, M. Is There Overtourism in Santiago de Compostela? Contributions for an Ongoing Debate. Bol. Asoc. Geogr. Esp. 2019, 83, 1-48. [CrossRef]

15. UNWTO. Glossary of Tourism Terms. Available online: https://www.unwto.org/glossary-tourism-terms (accessed on 11 July 2021).

16. Centro de Estudos Avanzados (CETUR). Estudo Da Caracterización Da Demanda Turística de Santiago de Compostela Ano 2018; CETUR: Santiago de Compostela, Spain, 2019. Available online: https://www.santiagoturismo.com/files/2019/08/INFORMEANUAL2 018.pdf (accessed on 11 July 2021).

17. Turismo de Santiago de Compostela y Sus Alrededores. Plan Estratégico de Turismo de Santiago de Compostela 2017-2022. 2018. Available online: https:/ / www.santiagoturismo.com/plan-estratexico-de-turismo-2017-2022 (accessed on 11 July 2021).

18. Anton-Clavé, S.; Calabuig, J. Planificación y Gestión de Destinos Turísticos; IUP-Grupo Santillana: Madrid, Spain, 2005.

19. Mowforth, M.; Munt, I. Tourism and Sustainability: Development and New Tourism in the Third World; Routledge: London, UK; New York, NY, USA, 2003. [CrossRef]

20. Rasoolimanesh, S.M.; Ringle, C.M.; Jaafar, M.; Ramayah, T. Urban vs. Rural Destinations: Residents' Perceptions, Community Participation and Support for Tourism Development. Tour. Manag. 2017, 60, 147-158. [CrossRef] 
21. Jaafar, M.; Rasoolimanesh, S.M.; Lonik, K.A.T. Tourism Growth and Entrepreneurship: Empirical Analysis of Development of Rural Highlands. Tour. Manag. Perspect. 2015, 14, 17-24. [CrossRef]

22. Prayag, G.; Hosany, S.; Nunkoo, R.; Alders, T. London Residents' Support for the 2012 Olympic Games: The Mediating Effect Ofoverall Attitude. Tour. Manag. 2013, 36, 629-640. [CrossRef]

23. Stylidis, D.; Biran, A.; Sit, J.; Szivas, E.M. Residents' Support for Tourism Development: The Role of Residents' Place Image and Perceived Tourism Impacts. Tour. Manag. 2014, 45, 260-274. [CrossRef]

24. Sharpley, R.; Telfer, D.J. Tourism and Development in the Developing World; Routledge: London, UK; New York, NY, USA, 2008.

25. Sharpley, R. Host Perceptions of Tourism: A Review of the Research. Tour. Manag. 2014, 42, 37-49. [CrossRef]

26. Rasoolimanesh, S.M.; Jaafar, M.; Kock, N.; Ramayah, T. A Revised Framework of Social Exchange Theory to Investigate the Factors Influencing Residents' Perceptions. Tour. Manag. Perspect. 2015, 16, 335-345. [CrossRef]

27. Gabriel, L.P.M.C.; Soares, J.R.R.; Godoi, C.K. O Uso Turístico Do Património: Congruências e Incongruências No Discurso de Residentes e Não Residentes de Uma Cidade Património Da Humanidade. In Sociedade, Economia e Património num Cenário Tendente a uma Maior Coesão Territorial; FLUP: Porto, Porutgal, 2017.

28. Eshliki, S.A.; Kaboudi, M. Community Perception of Tourism Impacts and Their Participation in Tourism Planning: A Case Study of Ramsar, Iran. Procedia Soc. Behav. Sci. 2012, 36, 333-341. [CrossRef]

29. Williams, J.; Lawson, R. Community Issues and Resident Opinions of Tourism. Ann. Tour. Res. 2001, 28, 269-290. [CrossRef]

30. Besculides, A.; Lee, M.E.; McCormick, P.J. Resident's Perceptions of the Cultural Benefits of Tourism. Ann. Tour. Res. 2002, 29, 303-319. [CrossRef]

31. Kuvan, Y.; Akan, P. Residents' Attitudes toward General and Forest-Related Impacts of Tourism: The Case of Belek, Antalya. Tour. Manag. 2005, 26, 691-706. [CrossRef]

32. Jackson, L.A. Residents' Perceptions of the Impacts of Special Event Tourism. J. Place Manag. Dev. 2008, 1, 240-255. [CrossRef]

33. Sharma, B.; Dyer, P. Examen de Diverses Perceptions de Résidents: Impacts Du Tourisme et Variables Démographiques. Tour. Geogr. 2009, 11, 187-213. [CrossRef]

34. Monjardino, I.C.C. Indicadores de Sustentabilidade do Turismo nos Açores: O Papel das Opiniões e da Atitude dos Residentes Face ao Turismo na Região. In 15 Congresso da APDR—Redes e Desenvolvimento Regional; Praia, Cabo Verde. 2009. Available online: http:/ / www.apdr.pt/congresso/2009/pdf/Sess\%C3\%A3o\%2014/29A.pdf (accessed on 19 August 2021).

35. Vareiro, L.; Santos, J.F.; Remoaldo, P.C.; Ribeiro, J.C. Evaluating the Guimarães 2012 European Capital of Culture: National and International Tourists' Behaviors and Perceptions. Event Manag. 2016, 20, 81-97. [CrossRef]

36. Faulkner, B.; Tideswell, C. A Framework for Monitoring Community Impacts of Tourism. J. Sustain. Tour. 1997, 5, 3-28. [CrossRef]

37. Mcdowall, S.; Choi, Y. A Comparative Analysis of Thailand Residents' Perception of Tourism's Impacts. J. Qual. Assur. Hosp. Tour. 2010, 11, 36-55. [CrossRef]

38. Vareiro, L.C.M.D.; Remoaldo, P.C.; Cadima Ribeiro, J.A. Residents' Perceptions of Tourism Impacts in Guimarães (Portugal): A Cluster Analysis. Curr. Issues Tour. 2013, 16, 535-551. [CrossRef]

39. The Adecco Group Institute. VII Monitor Adecco Sobre Salarios: España En El Contexto Europeo. 2020. Available online: https:/ / www.adeccoinstitute.es/informes/vii-monitor-adecco-sobre-salarios-espana-en-el-contexto-europeo/ (accessed on 11 July 2021). 